\title{
Neuroendovascular Cerebral Sinus Stenting in Idiopathic Intracranial Hypertension
}

\author{
Fawaz Al-Mufti ${ }^{a-c}$ Vincent Dodson ${ }^{c}$ Krishna Amuluruc, d Jessy Walia ${ }^{\mathrm{e}}$ \\ Ethan Wajswol $^{\mathrm{C}}$ Rolla Nuoman ${ }^{\mathrm{e}}$ Irwin A. Keller ${ }^{\mathrm{g}}$ Steven Schonfeldg \\ Sudipta Roychowdhuryg Gaurav Gupta ${ }^{f}$ \\ ${ }^{a}$ Department of Neurosurgery, Westchester Medical Center at New York Medical College, \\ Valhalla, NY, USA; 'b Department of Neurology, Robert Wood Johnson Medical School, \\ Rutgers University, New Brunswick, NJ, USA; ' Department of Neurosurgery, New Jersey \\ Medical School, Rutgers University, Newark, NJ, USA; ${ }^{d}$ Department of Neurointerventional \\ Radiology, University of Pittsburgh, Hamot, Erie, PA, USA; e Department of Neurology, New

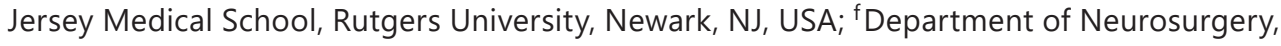 \\ Robert Wood Johnson Medical School, Rutgers University, New Brunswick, NJ, USA; \\ gDepartment of Radiology, Robert Wood Johnson Medical School, Rutgers University, \\ New Brunswick, NJ, USA
}

\section{Keywords}

Idiopathic intracranial hypertension $\cdot$ Venous sinus stent $\cdot$ Headache $\cdot$ Visual loss

\begin{abstract}
Idiopathic intracranial hypertension $(\mathrm{IIH})$ is a rare, ill-understood disease of significant morbidity. Because the pathophysiology is poorly understood, treatment protocols are not uniform and are directed towards alleviating the most common symptoms: headache and visual loss. In this review, we analyze 25 case series, all of which included IIH patients $(n=408)$ who were treated with placement of a venous sinus stent. Among 342 patients who had headache, 240 patients (70.2\%) had improvement or resolution of headache after the stent insertion. Of the 217 patients documented to have visual problems, visual acuity was improved or stabilized in 161 patients (74.2\%). Of the 304 patients with papilledema, 257 showed resolution or improved (84.5\%). Of the 124 patients who presented with pulsatile tinnitus, it was resolved in 110 patients (88.7\%) after stent placement. Endovascular management of dural sinus stenosis is therefore clinically efficacious in patients with $\mathrm{IH}$ who have failed medical and surgical therapy.

(C) 2019 S. Karger AG, Basel
\end{abstract}




\section{Introduction}

Idiopathic intracranial hypertension (IIH), also known as pseudotumor cerebri, is a progressive disease characterized by headache, visual symptoms, tinnitus, and evidence of elevated CSF pressure on lumbar puncture. It has a prevalence of $0.9-1.07 / 100,000$ in North America; however, when the criteria are modified to include only overweight women aged 20-44 years, the prevalence rises to 15-19/100,000 [1]. The original diagnostic criteria were proposed by Dandy, but with deeper understanding of the disease and advances in neuroimaging, these criteria have been modified over time. The current criteria as proposed by Friedman and Jacobson [2] in 2002 include: (1) signs and symptoms attributable only to elevated intracranial pressure (ICP), (2) CSF opening pressure of $>25 \mathrm{~cm} \mathrm{H}_{2} \mathrm{O}$, (3) normal CSF composition, and (4) no evidence of mass lesion or other structural causes using modern imaging techniques [2].

\section{Pathophysiology}

The pathophysiology of IIH has been a subject of constant debate and many theories have been proposed to explain the underlying mechanism of decreased CSF reabsorption and intracranial venous hypertension. Some of these theories include structural abnormalities within arachnoid granulations, dural venous sinus stenosis, or a combination of both. A hypothetical mechanism has been proposed which states that regardless of the initial cause of focal stenosis, venous hypertension proximal to the stenotic area leads to a further increase in ICP and subsequent worsening of stenosis, resulting in a positive feedback cycle [3]. Given the fact that stenosis of the transverse sinus is also present in asymptomatic patients, it is unclear whether it is a cause or a consequence of increased ICP. Nonetheless, there exists a hypothesis that by breaking the positive feedback and treating the focal stenosis, there is a chance to lower the ICP [4].

\section{Diagnosis and Assessment}

When papilledema is identified, it is critical to measure the blood pressure to exclude malignant hypertension. All mandatory tests of visual function should be recorded, including visual acuity, color vision, pupil examination, a dilated eye examination to document the optic nerve head, and macular findings to exclude an ocular cause of bilateral disc edema [5]. Quantification of disc edema is done using optical coherence tomography, which permits high-resolution noninvasive cross-sectional imaging of the neurosensory retina. Once papilledema has been diagnosed, brain imaging has a central role in excluding space-occupying lesions, obstructive hydrocephalus, and cerebral venous thrombosis. MRIs of the head and orbits with intravenous contrast and MR/CT venography should be performed [5]. The most commonly observed radiological signs of raised ICP are an empty sella, flattening of the posterior globes at the insertion of the optic nerves, protrusion of the optic nerve head into the vitreous, tortuosity of the intraorbital optic nerve, and demonstration of sinus stenosis on MR venography. Following imaging, lumboperitoneal shunting is mandatory to record the CSF opening pressure and exclude secondary causes of increased ICP. In addition to contemporary diagnostic modalities, venography with manometry and intravascular ultrasound should also be considered to assess the transmural pressure gradient across the stenotic segment. 


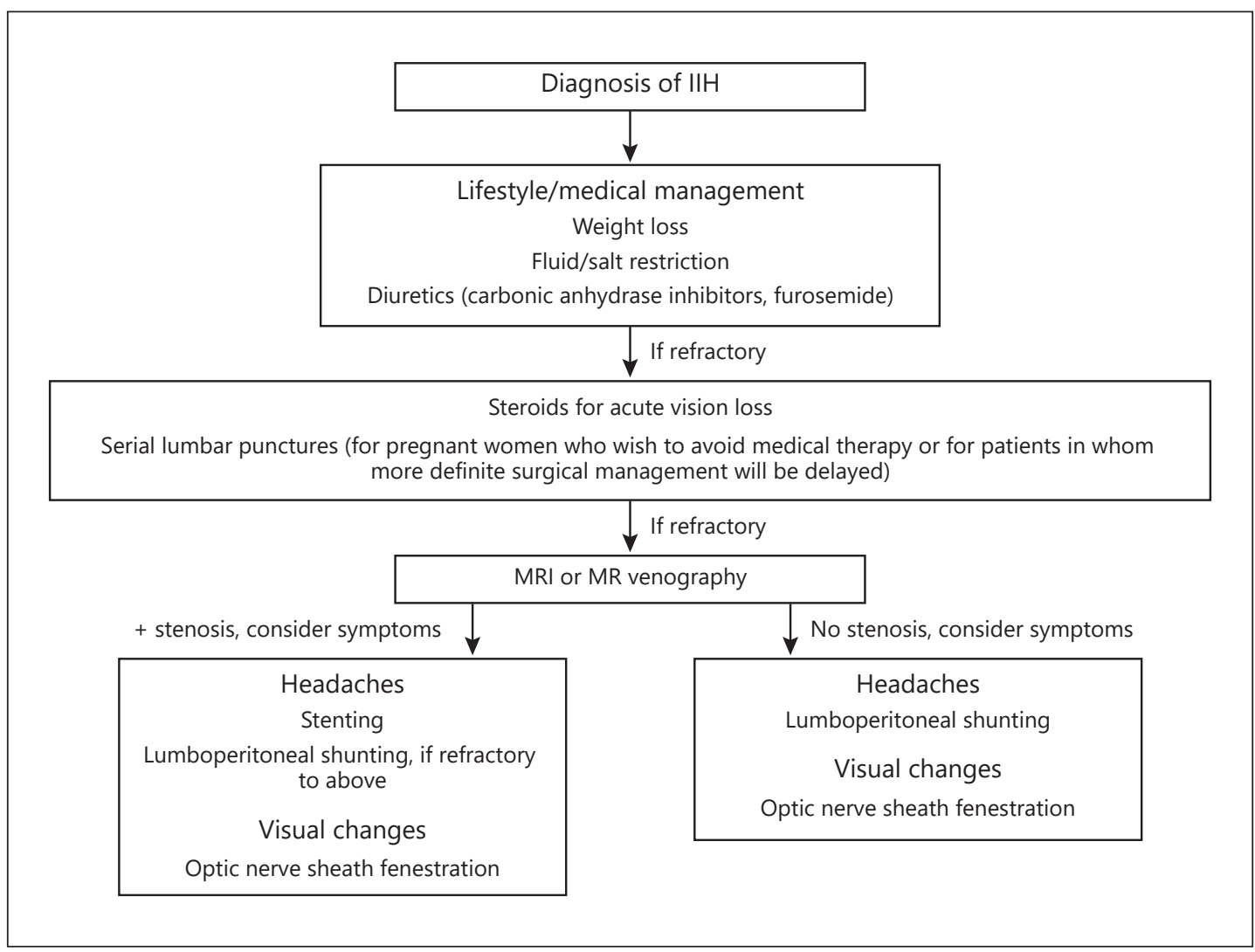

Fig. 1. Treatment algorithm for idiopathic intracranial hypertension (IIH).

\section{Treatment}

Because CSF dynamics are complex and not very well understood, the management algorithm is not well established (Fig. 1). It can be subdivided into conservative or medical management, followed by surgical management if the patient fails the medical management or alarming symptoms are present. The goal of the management is to preserve visual function and reduce headache disability. Obese patients are encouraged to lose weight and carbonic anhydrase inhibitors are the first line of medical therapy [6]. Traditionally, repeated lumbar punctures were performed but the evidence of this practice having any long-term benefit is lacking in the literature.

If the patient fails medical management or there is evidence of severe optic neuropathy that can lead to permanent vision loss, surgical options are then considered. These include optic nerve sheath fenestration (ONSF), CSF diversion procedures, including either lumboperitoneal or ventriculoperitoneal shunting [7], bariatric surgery for obesity [8], and the newly introduced transverse sinus stenting. In IIH patients with focal venous sinus stenosis, emphasis on the management of sinus stenosis by stenting is a novel, emerging treatment option providing very satisfactory clinical outcomes and low rates of complication and revision. Among all of the surgical options, the long-term outcomes of endovascular stenting with regards to visual function and headache when followed for 1 year were most promising, with improvement in visual acuity in $78 \%$ of cases and headache resolution in $77 \%$ of cases. 
Table 1. Summary of clinical outcomes

\begin{tabular}{llllll}
\hline Study & $\begin{array}{l}\text { Total } \\
\text { patients }\end{array}$ & Headache & $\begin{array}{l}\text { Vision } \\
\text { improvement }\end{array}$ & Papilledema & $\begin{array}{l}\text { Pulsatile } \\
\text { tinnitus }\end{array}$ \\
\hline Higgins et al., 2002 [10] & 1 & $1 / 1$ & $\mathrm{NR}$ & $1 / 1$ & $\mathrm{NR}$ \\
Higgins et al., 2003 [15] & 12 & $7 / 12$ & $7 / 12$ & $5 / 8$ & $\mathrm{NR}$ \\
Ogungbo et al., 2003 [19] & 1 & $1 / 1$ & $1 / 1$ & $1 / 1$ & $\mathrm{NR}$ \\
Owler et al., 2003 [20] & 4 & $4 / 4$ & $4 / 4$ & $2 / 3$ & $\mathrm{NR}$ \\
Rajpal et al., 2005 [21] & 1 & $1 / 1$ & $1 / 1$ & $1 / 1$ & $\mathrm{NR}$ \\
Donnet et al., 2008 [22] & 10 & $8 / 10$ & $7 / 8$ & $10 / 10$ & $5 / 5$ \\
Paquet et al., 2008 [23] & 1 & $1 / 1$ & $1 / 1$ & $1 / 1$ & $\mathrm{NR}$ \\
Arac et al., 2009 [24] & 1 & $1 / 1$ & $\mathrm{NR}$ & $\mathrm{NR}$ & $1 / 1$ \\
Bussière et al., 2010 [25] & 10 & $10 / 10$ & $4 / 4$ & $10 / 10$ & $\mathrm{NR}$ \\
Zheng et al., 2010 [26] & 1 & $1 / 1$ & $1 / 1$ & $1 / 1$ & $\mathrm{NR}$ \\
Albuquerque et al., 2011 [14] & 15 & $12 / 15$ & $\mathrm{NR}$ & $\mathrm{NR}$ & $\mathrm{NR}$ \\
Kumpe et al., 2012 [11] & 18 & $10 / 13$ & $15 / 15$ & $15 / 16$ & $\mathrm{NR}$ \\
Ahmed et al., 2011 [12] & 52 & $35 / 43$ & $9 / 13$ & $45 / 45$ & $17 / 17$ \\
Lazzaro et al., 2012 [27] & 3 & $2 / 3$ & $3 / 3$ & $2 / 2$ & $1 / 1$ \\
Fields et al., 2013 [28] & 15 & $10 / 15$ & $13 / 14$ & $15 / 15$ & $11 / 14$ \\
Radvany et al., 2013 [29] & 12 & $7 / 12$ & $11 / 12$ & $11 / 12$ & $11 / 11$ \\
Elder et al., 2015 [30] & 4 & $4 / 4$ & $2 / 4$ & $3 / 4$ & $2 / 2$ \\
Teleb et al., 2015 [31] & 18 & $10 / 18$ & $14 / 18$ & $18 / 18$ & $4 / 5$ \\
Boddu et al., 2016 [32] & 37 & $\mathrm{NR}$ & $\mathrm{NR}$ & $\mathrm{NR}$ & $28 / 29$ \\
Satti et al., 2017 [33] & 43 & $27 / 43$ & $15 / 35$ & $13 / 22$ & $\mathrm{NR}$ \\
Aguilar-Pérez et al., 2017 [34] & 51 & $31 / 37$ & $31 / 38$ & $42 / 50$ & $9 / 9$ \\
Dinkin and Patsalides, 2017 [35] & 13 & $11 / 13$ & $10 / 10$ & $11 / 13$ & $11 / 11$ \\
Shields et al., 2019 [36] & 42 & $18 / 42$ & NR & $29 / 39$ & NR \\
Asif et al., 2018 [38] & 41 & $26 / 40$ & $12 / 23$ & $19 / 30$ & $10 / 19$ \\
Miyaichi et al., 2018 [37] & 2 & $2 / 2$ & NR & $2 / 2$ & NR \\
\hline Totals & 408 & $240 / 342$ & $161 / 217$ & $257 / 304$ & $110 / 124$ \\
& & $(70.2 \%)$ & $(74.2 \%)$ & $(84.5 \%)$ & $(88.7 \%)$ \\
\hline
\end{tabular}

NR, not reported.

\section{Methods}

Using PubMed, we performed a search of the English language literature with several combinations of the keywords "Idiopathic Intracranial Hypertension," "Pseudotumor Cerebri," "Benign Intracranial Hypertension," "Endovascular," "Stent," and "Venous Sinus Stenting" to identify studies published after 1970 in which cases of IIH were treated with placement of a venous sinus stent. We identified 24 case series (a total of 367 patients) that met our inclusion criteria.

\section{Results}

Among 342 patients who had headache, 240 patients (70.2\%) had improvement or resolution of headache after the stent insertion. Of the 217 patients documented to have visual problems, visual acuity was improved or stabilized in 161 patients (74.2\%). Of the 304 patients with papilledema, 257 showed resolution or improved (84.5\%). Of the 124 patients who presented with pulsatile tinnitus, it was resolved in 110 patients (88.7\%) after stent placement. Table 1 summarizes the patient outcomes for each of the included studies. A 
Table 2. Major and minor criteria for cerebral sinus stenting [9]

Major criteria for cerebral sinus stenting (all required)

Refractory to maximal medical therapy

Pressure gradient across stenosis $8 \mathrm{~mm} \mathrm{Hg}$

ICP $22 \mathrm{~mm} \mathrm{Hg}$

Visual changes, papilledema, focal neurological deficits, severely disabling headache

No contraindication to dual platelet therapy

Minor criteria for cerebral sinus stenting (one required)

Intolerance to repeated lumbar puncture or lumbar drain

Dural sinus stenosis of $50 \%$ on CT or MR venography

Failed surgical interventions, including shunting or optic nerve fenestration

Pulsatility detected by manometry which is reduced after stenosis

Patient preference

common complication of venous sinus stenting is ipsilateral headache, which occurs in $20-100 \%$ of cases and normally resolves within a few days after the procedure. Intracranial hemorrhage is a serious complication that is rarely seen after the procedure (4-6\%). Proximal stent stenosis was found in some studies with unclear etiology. In contrast to arterial stenting, in-stent restenosis is very rare in venous sinus stenting. Aspirin and clopidogrel are generally required for 3-4 days prior to stent placement and are continued for 3-6 months, after which time clopidogrel is discontinued.

\section{Discussion}

\section{Pathophysiology}

IIH is a disorder of poorly understood pathophysiology that is progressive in nature; permanent vision loss is found in $25 \%$ of cases and 1-2\% of new cases each year are registered blind [5]. Recently, several groups have been investigating this pathophysiology by undertaking catheter studies in the venous sinuses (cerebral venography) and recording intra-sinus pressures (manometry). These groups have documented high pressures in the venous sinuses in patients with IIH. The high pressures are occasionally secondary to systemic venous hypertension but are more often the result of stenotic lesions of the venous sinuses, causing partial obstruction to cranial venous outflow. This has led some investigators to propose intracranial venous hypertension as the common pathway in the etiology of IIH [4].

The efficacy of stenting is predicated on the notion that venous outflow obstruction plays some part in the etiology of signs and symptoms in IIH patients. If venous outflow obstruction were the cause, then dilating the stenosis and abolishing the pressure gradient should be curative. If the lateral sinus stenoses were secondary to raised ICP in patients who benefited from stenting, these stenoses must have been responsible for an increase in ICP large enough to render them symptomatic. In the review series, the endovascular stent placement does appear to be an efficacious treatment option with significant resolution of headache, papilledema, and pressure gradients but the analysis is limited by the retrospective nature of the studies analyzed and the lack of coordinated data reported in the studies considered. This leads to a decreased power in the analysis of certain variables included in this report. Moreover, the criteria for considering endovascular stenting as the treatment modality needs to be defined. One study proposed a set of criteria for cerebral venous stenting, which included major and minor criteria [9]. According to this study, the major criteria the patient should demonstrate to indicate cerebral venous stenting are failed maximal medical therapy or 
fulminant course refractory to medical treatment with rapidly worsening vision, a pressure gradient across the stenosis of greater than or equal to $8 \mathrm{~mm} \mathrm{Hg}$, an ICP of greater than or equal to $22 \mathrm{~mm} \mathrm{Hg}$, visual changes, papilledema, other focal objective neurological symptoms, or severely disabling headaches, and no contraindications to dual antiplatelet therapy. In addition to demonstrating all of the aforementioned major criteria, the patient must also demonstrate at least one of the following minor criteria: intolerance to repeated lumbar puncture or lumbar drain, dural sinus stenosis of greater than or equal to $50 \%$ on CT or MR venography, failed surgical shunting procedure or optic nerve fenestration, pulsatility demonstrated by manometry which is reduced after stenosis, or the patient's own preference for the procedure [9]. These major and minor criteria as described by Teleb et al. [9] are summarized in Table 2.

\section{Complications of Stenting}

Even though endovascular stenting has shown promising results in alleviating the symptoms associated with IIH, it is not without its complications. A common complication of venous sinus stenting is ipsilateral headache, which occurs in $20-100 \%$ of cases and normally resolves within a few days after the procedure. Much more uncommon is the incidence of intracranial hemorrhage. These complications may be due to residual venous outflow obstruction [10,11]. Ahmed et al. [12] reported two patients out of 52 (4\%) with major cerebrovascular complications. One patient developed a subdural hematoma caused by the guidewire perforating a vein and another patient developed subarachnoid and intracerebral bleeding at the time of emergency treatment for fulminant IIH [12]. Other potential complications include venous sinus perforation, the development of a new stenosis proximal to the stent, and thrombosis [12-15]. The necessity to re-stent is not common, but it is nonetheless an appreciable possibility for some patients [12]. In their retrospective review of 52 patients, Ahmed et al. [12] found that $6(12 \%)$ required re-stenting.

\section{Comparisons with Other Treatments}

In addition to endovascular stenting, other surgical procedures have resulted in some success in alleviating the symptoms of IIH. Some patients are treated with ONSF; however, ONSF seems to be more effective in treating symptoms specific to visual impairment and it is less effective in treating the most commonly cited symptom (headaches) [16]. ONSF was specifically shown to improve visual acuity, visual fields, and color vision. Another surgical procedure routinely conducted is ventriculoperitoneal shunting. Compared to lumboperitoneal shunting, ventriculoperitoneal shunting results in a lesser likelihood of need for shunt revision, decreased length of stay, and decreased overall charges to the health care system [17]. However, compared to endovascular stenting, ventriculoperitoneal shunting demonstrated less of an improvement in visual acuity and headaches [18]. Overall, endovascular stenting for IIH seems to be a much safer and efficacious treatment when compared to ONSF, lumboperitoneal shunt, and ventriculoperitoneal shunt. Although the preliminary data supports this observation, more comprehensive clinical trials are needed to support the procedure's efficacy and safety.

\section{Conclusion}

Endovascular management of dural sinus stenosis appears technically feasible and safe. It is clinically efficacious in patients with IIH who have failed medical and surgical therapy with dural sinus stenosis. Nonetheless, there is a need for a formal multicenter clinical trial to prospectively measure safety and long-term efficacy of this procedure. 


\section{Disclosure Statement}

The authors have no personal or institutional interest with regards to the authorship and/or publication of this paper.

\section{Funding Sources}

This research received no specific grant from any funding agency in the public, commercial, or not-forprofit sectors.

\section{References}

1 Durcan FJ, Corbett JJ, Wall M. The incidence of pseudotumor cerebri. Population studies in Iowa and Louisiana. Arch Neurol. 1988 Aug;45(8):875-7.

2 Friedman DI, Jacobson DM. Diagnostic criteria for idiopathic intracranial hypertension. Neurology. 2002 Nov; 59(10):1492-5.

3 Owler BK, Parker G, Halmagyi GM, Johnston IH, Besser M, Pickard JD, et al. Cranial venous outflow obstruction and pseudotumor Cerebri syndrome. Adv Tech Stand Neurosurg. 2005;30:107-74.

4 King JO, Mitchell PJ, Thomson KR, Tress BM. Cerebral venography and manometry in idiopathic intracranial hypertension. Neurology. 1995 Dec;45(12):2224-8.

5 Mollan SP, Ali F, Hassan-Smith G, Botfield H, Friedman DI, Sinclair AJ. Evolving evidence in adult idiopathic intracranial hypertension: pathophysiology and management. J Neurol Neurosurg Psychiatry. 2016 Sep; 87(9): 982-92.

6 Celebisoy N, Gökçay F, Sirin H, Akyürekli O. Treatment of idiopathic intracranial hypertension: topiramate vs acetazolamide, an open-label study. Acta Neurol Scand. 2007 Nov;116(5):322-7.

7 Sinclair AJ, Kuruvath S, Sen D, Nightingale PG, Burdon MA, Flint G. Is cerebrospinal fluid shunting in idiopathic intracranial hypertension worthwhile? A 10-year review. Cephalalgia. 2011 Dec;31(16):1627-33.

8 Spitze A, Malik A, Lee AG. Surgical and endovascular interventions in idiopathic intracranial hypertension. Curr Opin Neurol. 2014 Feb;27(1):69-74.

9 Teleb MS, Cziep ME, Lazzaro MA, Gheith A, Asif K, Remler B, et al. Idiopathic Intracranial Hypertension. A Systematic Analysis of Transverse Sinus Stenting. Intervent Neurol. 2013;2(3):132-43.

10 Higgins JN, Owler BK, Cousins C, Pickard JD. Venous sinus stenting for refractory benign intracranial hypertension. Lancet. 2002 Jan;359(9302):228-30.

11 Kumpe DA, Bennett JL, Seinfeld J, Pelak VS, Chawla A, Tierney M. Dural sinus stent placement for idiopathic intracranial hypertension. J Neurosurg. 2012 Mar;116(3):538-48.

12 Ahmed RM, Wilkinson M, Parker GD, Thurtell MJ, Macdonald J, McCluskey PJ, et al. Transverse sinus stenting for idiopathic intracranial hypertension: a review of 52 patients and of model predictions. AJNR Am J Neuroradiol. 2011 Sep;32(8):1408-14.

13 Ahmed R, Friedman DI, Halmagyi GM. Stenting of the transverse sinuses in idiopathic intracranial hypertension. J Neuroophthalmol. 2011 Dec;31(4):374-80.

14 Albuquerque FC, Dashti SR, Hu YC, Newman CB, Teleb M, McDougall CG, et al. Intracranial venous sinus stenting for benign intracranial hypertension: clinical indications, technique, and preliminary results. World Neurosurg. 2011 May-Jun;75(5-6):648-52.

15 Higgins JN, Cousins C, Owler BK, Sarkies N, Pickard JD. Idiopathic intracranial hypertension: 12 cases treated by venous sinus stenting. J Neurol Neurosurg Psychiatry. 2003 Dec;74(12):1662-6.

16 Obi EE, Lakhani BK, Burns J, Sampath R. Optic nerve sheath fenestration for idiopathic intracranial hypertension: a seven year review of visual outcomes in a tertiary centre. Clin Neurol Neurosurg. 2015 Oct;137: 94-101.

17 Menger RP, Connor DE Jr, Thakur JD, Sonig A, Smith E, Guthikonda B, et al. A comparison of lumboperitoneal and ventriculoperitoneal shunting for idiopathic intracranial hypertension: an analysis of economic impact and complications using the Nationwide Inpatient Sample. Neurosurg Focus. 2014 Nov;37(5):E4.

18 Lai LT, Danesh-Meyer HV, Kaye AH. Visual outcomes and headache following interventions for idiopathic intracranial hypertension. J Clin Neurosci. 2014 Oct;21(10):1670-8.

19 Ogungbo B, Roy D, Gholkar A, Mendelow AD. Endovascular stenting of the transverse sinus in a patient presenting with benign intracranial hypertension. Br J Neurosurg. 2003 Dec;17(6):565-8.

20 Owler BK, Parker G, Halmagyi GM, Dunne VG, Grinnell V, McDowell D, et al. Pseudotumor cerebri syndrome: venous sinus obstruction and its treatment with stent placement. J Neurosurg. 2003 May; 98(5):1045-55.

21 Rajpal S, Niemann DB, Turk AS. Transverse venous sinus stent placement as treatment for benign intracranial hypertension in a young male: case report and review of the literature. J Neurosurg. 2005 Apr;102(3 Suppl): 342-6. 
22 Donnet A, Metellus P, Levrier O, Mekkaoui C, Fuentes S, Dufour H, et al. Endovascular treatment of idiopathic intracranial hypertension: clinical and radiologic outcome of 10 consecutive patients. Neurology. 2008 Feb; 70(8):641-7.

23 Paquet C, Poupardin M, Boissonnot M, Neau JP, Drouineau J. Efficacy of unilateral stenting in idiopathic intracranial hypertension with bilateral venous sinus stenosis: a case report. Eur Neurol. 2008;60(1):47-8.

24 Arac A, Lee M, Steinberg GK, Marcellus M, Marks MP. Efficacy of endovascular stenting in dural venous sinus stenosis for the treatment of idiopathic intracranial hypertension. Neurosurg Focus. 2009 Nov;27(5):E14.

25 Bussière M, Falero R, Nicolle D, Proulx A, Patel V, Pelz D. Unilateral transverse sinus stenting of patients with idiopathic intracranial hypertension. AJNR Am J Neuroradiol. 2010 Apr;31(4):645-50.

26 Zheng H, Zhou M, Zhao B, Zhou D, He L. Pseudotumor cerebri syndrome and giant arachnoid granulation: treatment with venous sinus stenting. J Vasc Interv Radiol. 2010 Jun;21(6):927-9.

27 Lazzaro MA, Darkhabani Z, Remler BF, Hong SH, Wolfe TJ, Zaidat 00, et al. Venous sinus pulsatility and the potential role of dural incompetence in idiopathic intracranial hypertension. Neurosurgery. 2012 Oct; 71(4): 877-83.

28 Fields JD, Javedani PP, Falardeau J, Nesbit GM, Dogan A, Helseth EK, et al. Dural venous sinus angioplasty and stenting for the treatment of idiopathic intracranial hypertension. J Neurointerv Surg. 2013 Jan;5(1):62-8.

29 Radvany MG, Solomon D, Nijjar S, Subramanian PS, Miller NR, Rigamonti D, et al. Visual and neurological outcomes following endovascular stenting for pseudotumor cerebri associated with transverse sinus stenosis. J Neuroophthalmol. 2013 Jun;33(2):117-22.

30 Elder BD, Goodwin CR, Kosztowski TA, Radvany MG, Gailloud P, Moghekar A, et al. Venous sinus stenting is a valuable treatment for fulminant idiopathic intracranial hypertension. J Clin Neurosci. 2015 Apr;22(4):685-9.

31 Teleb MS, Cziep ME, Issa M, Lazzaro M, Asif K, Hong SH, et al. Stenting and angioplasty for idiopathic intracranial hypertension: a case series with clinical, angiographic, ophthalmological, complication, and pressure reporting. J Neuroimaging. 2015 Jan-Feb;25(1):72-80.

32 Boddu S, Dinkin M, Suurna M, Hannsgen K, Bui X, Patsalides A. Resolution of Pulsatile Tinnitus after Venous Sinus Stenting in Patients with Idiopathic Intracranial Hypertension. PLoS One. 2016 Oct;11(10):e0164466.

33 Satti SR, Leishangthem L, Spiotta A, Chaudry MI. Dural venous sinus stenting for medically and surgically refractory idiopathic intracranial hypertension. Interv Neuroradiol. 2017 Apr;23(2):186-93.

34 Aguilar-Pérez M, Martinez-Moreno R, Kurre W, Wendl C, Bäzner H, Ganslandt O, et al. Endovascular treatment of idiopathic intracranial hypertension: retrospective analysis of immediate and long-term results in 51 patients. Neuroradiology. 2017 Mar;59(3):277-87.

35 Dinkin MJ, Patsalides A. Venous Sinus Stenting in Idiopathic Intracranial Hypertension: Results of a Prospective Trial. J Neuroophthalmol. 2017 Jun;37(2):113-21.

36 Shields LB, Shields CB, Yao TL, Plato BM, Zhang YP, Dashti SR. Endovascular Treatment for Venous Sinus Stenosis in Idiopathic Intracranial Hypertension: An Observational Study of Clinical Indications, Surgical Technique, and Long-Term Outcomes. World Neurosurg. 2019 Jan;121:e165-e171.

37 Miyachi S, Hiramatsu R, Ohnishi H, Takahashi K, Kuroiwa T. Endovascular Treatment of Idiopathic Intracranial Hypertension with Stenting of the Transverse Sinus Stenosis. Neurointervention. 2018 Sep;13(2):138-43.

38 Asif H, Craven CL, Siddiqui AH, Shah SN, Matloob SA, Thorne L, et al. Idiopathic intracranial hypertension: 120-day clinical, radiological, and manometric outcomes after stent insertion into the dural venous sinus. J Neurosurg. 2018 Sep;129(3):723-31. 